\title{
Social Capital and Health: What the Empirical Literature Teaches Us?
}

\author{
Thomas G. PODER (Corresponding author) \\ $\mathrm{PhD}$. in economics \\ UETMIS - CHUS - Hôpital Fleurimont, Sherbrooke - CANADA \\ CERDI - CNRS - Université d'Auvergne, Clermont 1 - FRANCE \\ Unité d'Évaluation des Technologies et Modes d'Interventions en Santé (UETMIS) \\ Centre Hospitalier Universitaire de Sherbrooke (CHUS) \\ Hôpital Fleurimont, 3001, 12e avenue nord, Sherbrooke J1H 5N4 \\ Québec, Canada \\ Tel: (1)-819-346-1110 \# 13496 E-mail: tpoder.chus@ssss.gouv.qc.ca
}

Jie HE

$\mathrm{PhD}$. in economics

Université de Sherbrooke - Département d'économique \& GREDI - CANADA

2500 Bd. Université, Sherbrooke J1K 2R1, Québec, Canada

E-mail: Jie.he@usherbrooke.ca

\begin{abstract}
Over the last two decades no single concept has more aggressively captured the scholarly imagination in diverse academic disciplines than social capital. Social scientists from various fields have posited its existence, deployed it in empirical studies, and have begun to suggest policy applications. As a result, social capital is now everywhere, but nobody knows how it actually works. And this problem is even more prevalent in health than in any other field. In this setting, this brief article sets out to investigate what is known so far about the associations between social capital and health, and offers suggestions as to how produce more health.
\end{abstract}

Keywords: Social capital, Health, Health behaviour

\section{Introduction}

An increasing number of authors now consider that therapeutic medicine is no longer adequate to improve the health of individuals (Evans et al., 1996; Wilkinson, 1996, 1999a, 1999b) and that many other elements must be taken into account. It is in this context that the theory of four capitals: physical, human, natural, and social should be included when formulating health policies.

As emphasised in Nettleton's book (1995), "The Sociology of Health and Illness", currently, there is a change of attitude in the perception of health problems. Although this perception is now arousing increasing interest, it is however a much older subject. Two thousand five hundred years ago, Hippocrates also associated health with the environment and the human soul. This view was almost abandoned during the "Enlightenment years", and especially during the seventeenth century, as being unscientific. Cartesianism mainly gave medicine a more scientific orientation. For Descartes, the soul cannot affect bodily functions, and each symptom has a specific cause that can be scientifically proven. This new doctrine caused many revolutionary scientific theories, including that of Pasteur on germs. Thus, given the huge progress in medicine during the nineteenth century and especially during the twentieth century, and despite the existence of competing theories about the origin of disease and illness (Tesh, 1988), the idea of a connection between psycho-socio-environmental and health factors has been regarded as negligible, even false for many scientists of the time. However, since it is statistically possible to perform international comparisons in terms of health policy, it is clear that therapeutic medicine -although essential- does not explain all the differences and there is a need to pay attention to these "old" ideas. Therefore, as regard to the long history of these "old" ideas, if the term social capital is relatively new (Hanifan, 1916), its implications are far from being new, which is the reason why we intend to identify the empirical possible effects of the various forms of social capital on the health of individuals. 


\section{How do social capital and heath connect?}

The basic idea is that there are social risk factors that can affect the health status of individuals. These social risk factors are most often long-term difficulties and negative events. The most frequent long-term difficulties include poverty, inadequate education, living in an unhealthy physical environment, and a high level of insecurity. Examples of negative events may relate to the loss of a partner, unemployment, forced migration, natural disasters, and so on. In many of these cases, social capital will be able to limit or reduce their negative effects. From this point of view, changes in social capital may be decisive. However, if social capital is important for health, it is quite hard to demonstrate its global effect inasmuch social capital is not made up of a single entity but of many different concepts underlining various aspects of social interactions. Indeed, social capital encompasses concepts such as networks (Bourdieu, 1980; Putnam, 1995, 2000), norms, confidence, reciprocity (Putnam, 1995; Coleman, 1988), and the strategic position (Burt, 1995). Given that social capital is declined in variations of substance and scales of such magnitude that it appears impossible to find in the literature a consensual definition of it, we decide in this paper to segment its principal components to identify their respective effects on health. As a consequence, we find that social capital, minimally defined by the quantity and quality of social interactions, has the possibility of affecting health through at least four mechanisms: 1) individual and 2) collective resources provided by social networks; 3) individual and 4) collective consequences of social norms.

\subsection{Individual resources provided by social networks}

Social capital may at first act as a resource to offset the negative effects resulting from unfavorable events or socioeconomic conditions and/or to better support their burden. There are two types of these resources: moral and material. On one hand, relationships shared through networks -family, friends, working colleagues, associations, and so on- provide a moral support. This moral support makes it possible to fight against feelings of vulnerability and insecurity resulting from life's daily difficulties. Individuals with a strong moral support know that they are less likely to be abandoned in the event of problems, allowing them to reduce the intensity and the frequency of their periods of stress and depression. This contributes to limiting the emergence of chronic diseases (Berkman, \& Syme, 1979; House et al., 1988; Berkman, 1995; Kawachi et al., 1996; Wilkinson, 1996, 2002; Brunner, 1997; McCulloch, 2001), or even infectious diseases -insofar as chronic stress exhausts the immunity system and makes it more vulnerable (Segerstrom, \& Miller, 2004). For example, the study by Locke and Collingan (1986) reveals that isolated people have a death rate four times higher than that of integrated ones; and, according to theses authors, this result can not only be explained in a trivial way, as, for instance, in case of domestic accidents, where a socially integrated person has a greater chance to make people realise his absence, and, therefore, to be rescued. So, well before the work of Segerstrom and Miler (2004) who provide a review of 300 medical analyses on the relationship between chronic stress and the immunity system, Locke and Collingan (1986) were already considering that psychoneuroimmunology is an unexplored and very important way that the body has of healing itself, and that social capital, in such configuration, has a vital role to play on the health of individual. On the other hand, the mobilization of material resources through the networks also allows a faster return to the initial situation because of easy access to more material elements that were lacking. Thus, social capital allows, for example, the mobilization of the necessary resources for the purchase of medicine without which the disease could have worsened or crippled the patient over a longer period (Ayé et al., 2002; Habtom, \& Ruys, 2007).

If such mechanisms seem to work at the level of single individuals, do they do so at the level of the entire community? Some studies have found that socially isolated individuals residing in cohesive communities do not seem to suffer the same harmful consequences in terms of health as those residing in communities that are less so. This would be the case of individuals living in the east of Boston (Seeman et al., 1993), or within Japanese communities in Hawaii (Reed et al., 1983). It would appear that social environments characterised by high levels of confidence tend to produce more individuals with a minimum of public responsibility toward each other. By contrast, social environments characterised by a strong mistrust, social dislocation, structural violence and a weak associative participation would lead to produce higher death rates through psychosocial mechanisms (Farmer, 1999, 2003; Wilkinson, 1996, 2002; Veenstra, 2002). However, certain studies carried out at the cross-country level contradict these results by showing that social capital does not explain or explain very little the differences in health between populations (Lynch et al., 2001; Kennelly et al., 2003; Poortinga, 2006a). These results can be partly explained by the fact that social capital is a very contextual concept and that the aggregation of data makes certain local specifications disappear. Moreover, as Hyypä and Mäki (2001) and Veenstra (2000) mentioned it, it is possible to find no relationship between social capital and health inasmuch the use of variables such as "participation in association" to indicate a stock of social capital can be misleading because it measures neither the degree of the participation nor the quality of the relationships. Finally, Poortinga (2006a) provides 
another explanation by postulating that social capital does not uniformly benefit individuals living in the same community or society.

\subsection{Collective resources provided by social networks}

Secondly, social capital, as a capacity of collective action, can also be perceived as a way for citizens to express to their peers and/or representatives their preferences for health. Indeed, in communities where the level of social capital is high, it is easier to effectively involve individuals in solving their problems. For example, establishing infrastructure that makes it possible to improve the health of individuals is often easier to accomplish in communities with a high level of social capital (Eng et al., 1990; Audibert, 1997; Sampson et al., 1997; Gebremedhin et al., 2004; Wakefield, \& Poland, 2005). However, it should be kept in mind that it is quite possible that a high level of social capital, such as religious beliefs and traditions, leads to negative results in terms of health, insofar as social capital is sometimes an element preventing economic and medical progress (Goldin, 1992).

\subsection{Individual consequences of social norms}

Thirdly, social capital can influence the health of individuals through two channels: the worthlessness of oneself and social control. First of all, people having little social capital can feel excluded and adopt harmful behaviors for themselves and their entourage. Indeed, people having such feelings often develop a bad image of themselves and feel useless, which leads them to low self-esteem and even stop making efforts to maintain good living conditions, for example, alcoholism, tobacco addiction, self-mutilation, and so on (Black Report, 1982, 1988), or even to no longer feel the need to respect others -violence, "abandonment" of children, and so on- (Kawachi et al., 1997, 1999; Kennedy et al., 1998; Wilkinson, 2002). On the contrary, a strong social capital can make a difference if practices favorable to health exist within the community, such as the practice of physical activities (Lindström et al., 2001) or the discouragement of smoking, taking drugs or drinking alcohol (Lindström, 2003; Greiner et al., 2004; Poortinga, 2006b; Siahpush et al., 2006). In such contexts, it is the impact of the reinforcement of enhancive behaviors and the control of deviant behaviors that is pointed out. Moreover, the theory of diffusion of the innovations (Rogers, 1983) suggests that innovative behaviors, when fully understood, propagate more quickly in communities showing high levels of cohesion and whose members know and trust each other.

\subsection{Collective consequences of social norms}

Finally, if the thesis of Putman et al. (1993) and Putnam (1995), according to which more social capital allows an improvement of institutional performances through the spread out of norms of reciprocity, trust and cooperation, proves to be exact -as seems to certify his work on the Italian regions (Putnam et al., 1983, 1993)-, the health of individuals should then benefit from a greater efficiency of the health system and also from an increase in the budget of the health system resulting from a greater economic growth. Moreover, this theory corresponds very well with that of Wilkinson (1996) who describes an interaction between social capital -or social cohesion- and the level of income inequality in a society. Indeed, for Wilkinson (1996), cohesive societies that have developed standards of solidarity would be less unequal, all else being equal, which would allow an equivalent reduction in the psychosocial consequences of inequality's perception on self-esteem, stress, anxiety, and anger, which in turn would reinforce the mechanism described by Putnam et al. (1993) and Putnam (1995) and trigger a virtuous circle.

\section{Conclusion}

To conclude, it appears that social capital is related to health through a large spectrum of phenomena. Undeniably, the massive use of this concept is relatively new with promising results. However, in turn, it should not overshadow the role of other factors in the reduction of health problems, but should attempt to insert it into a more general theory of health. In addition, works in the field of social capital should be dealt with caution, especially as this encompasses not one but several concepts. Indeed, the more these works are developed the more difficult they are to untangle: "When one scratches beneath the surface of social capital things quickly become more complicated" (Lynch et al., 2000, p.404). However, such a difficulty should lead us to more rigor and exhaustiveness in the measurement of various elements of social capital to help carry out investigations where it would be possible to assess -along with the more traditional determinants of health- the relative contribution of these different elements.

\section{References}

Audibert, M. (1997). La cohésion sociale est-elle un facteur de l'efficience technique des exploitations agricoles en économie de subsistance? Revue d'économie du développement, 3, 69-90. 
Ayé, M., Champagne, F., \& Contandriopoulos, A-P. (2002). Economic role of solidarity and social capital in accessing modern health care services in the Ivory Coast. Soc Sci Med, 55, 1929-1946.

Berkman, L. F. (1995). The Role of Social Relations in Health Promotion. Psychosom Med, 57, $245-254$.

Berkman, L. F., \& Syme, S. L. (1979). Social Networks, Host Resistance and Mortality: a Nine Year Follow-Up Study of Alameda County Residents. Am J Epidemiol, 109, 186-204.

Black, D., Morris, J. N., Smith, C., \& Townsend, P. (1982). In P. Townsend, \& N. Davidson (Eds.), Inequalities in health: the Black Report. New York: Penguin.

Black, D., Morris, J.N., Smith, C., Townsend, P., \& Whitehead, M. (1988). In P. Townsend, M. Whitehead, \& N. Davidson (Eds.). Inequalities in health: the Black Report and the Health Divid. London: Penguin.

Bourdieu, P. (1980). Le capital social : notes provisoires. Actes de la recherche en sciences sociales, 31, 2-3.

Brunner, E. J. (1997). Stress and the biology of inequality. BMJ, 314, 1472-1476.

Burt, R. (1995). Le capital social, les trous structuraux et l'entrepreneur. Revue française de sociologie, 36 (4), 599-628.

Coleman, J. S. (1988). Social Capital in the Creation of Human Capital. Am J Sociol, 94 (Supplement), 95-120.

Eng, E., Briscoe, J., \& Cunningham, A. (1990). Participation effect from water projects on EPI. Soc Sci Med, 30, 1349-1358.

Evans, R. G., Barer, M. L., \& Marmor, T. R. (1996). Être ou ne pas être en bonne santé. Montréal: Les Presses de l'Université de Montréal.

Farmer, P. (1999). Infections and Inequalities. Berkeley: University of California Press.

Farmer, P. (2003). Pathologies of Power. Health, Human Rights, and the New War on the Poor. Berkeley: University of California Press.

Gebremedhin, B., Pender, J., \& Tesfay, G. (2004). Collective action for grazing land management in crop-livestock mixed systems in the highlands of northern Ethiopia. Agricultural Systems, 82 (3), 273-290.

Goldin, L. R. (1992). Work and Ideology in the Maya Highlands of Guatemala: Economic Beliefs in the Context of Occupational Change. Economic Development and Cultural Change, 41 (1), 103-123.

Greiner, K. A., Li, C., Kawachi, I., Hunt, D. C., \& Ahluwalia, J. S. (2004). The relationships of social participation and community ratings to health and health behaviors in areas with high and low population density. Soc Sci Med, 59, 2303-2312.

Habtom, G. K., \& Ruys, P. (2007). Traditionnal risk-sharing arrangements and informal social insurance in Eritrea. Health Policy, 80, 218-235.

Hanifan, L. J. (1916). The rural school community center. Annals of the American Academy of Political and Social Science, 67, 130-138.

House, J-S., Landis, K. R., \& Umberson, D. (1988). Social Relationships and Health. Science, 214, $540-545$.

Hyypä, M., \& Mäki, J. (2001). Individual-level relationships between social capital and self-rated health in a bilingual community. Prev Med, 32, 148-155.

Kawachi, I., Colditz, G. A., Ascherio, A., Rimm, E. B., Giovannucci, E., Stampfer, M. J., \& Willett, W. C. (1996). A Prospective Study of Social Networks in Relation to Total Mortality and Cardiovascular Disease Incidence in Men. J Epidemiol Community Health, 50, 245-251.

Kawachi, I., Kennedy, B. P., Lochner, K., \& Prothrow-Stith, D. (1997). Social Capital, Income Inequality, and Mortality. Am J Public Health, 87, 1491-1498.

Kawachi, I., Kennedy, B., \& Wilkinson, R. G. (1999). Crime: social disorganisation and relative deprivation. Soc Sci Med, 48, 719-731.

Kennedy, B., Kawachi, I., Prothrow-Stith, D., Lochner, K., \& Gupta, V. (1998). Social capital, income inequality, and firearm violent crime. Soc Sci Med, 47 (1), 7-17.

Kennelly, B., O’Shea, E., \& Garvey, E. (2003). Social capital, life expectancy and mortality: a cross-national examination. Soc Sci Med, 56, 2367-2377.

Lindström, M. (2003). Social capital and the miniaturization of community among daily and intermittent smokers: a population-based study. Prev Med, 36, 177-184. 
Lindström, M., Hanson, B. S., \& Ostergren, P-O. (2001). Socioeconomic differences in leisure-time physical activity: The role of social participation and social capital in shaping health-related behaviour. Soc Sci Med, 52, 441-451.

Locke, S., \& Collingan, D. (1986). The Healer within: the new medicine of mind and body. New York: Dutton EP.

Lynch, J., Due, P., Muntaner, C., \& Davey Smith, G. (2000). Social capital-is it a good investment strategy for public health? J Epidemiol Community Health, 54, 404-408.

Lynch, J., Davey Smith, G., Hillemeier, M., Shaw, M., Raghunathan, T., \& Kaplan, G. (2001). Income inequality, the psychosocial environment, and health: Comparisons of wealthy nations. The Lancet, 358, 194-200.

McCulloch, A. (2001). Social environments and health: Cross sectional national survey. BMJ, 323, 208-209.

Nettleton, S. (1995). The Sociology of Health and Illness. Cambridge: Polity Press.

Poortinga, W. (2006a). Social capital: An individual or collective resource for health? Soc Sci Med, 62, 292-302.

Poortinga, W. (2006b). Do health behaviors mediate the association between social capital and health? Prev Med, 43, 6, 488-493.

Putnam, R. D. (1995). Bowling Alone: America's Declining Social Capital. Journal of Democracy, 6 (1), 65-78.

Putnam, R. D. (2000). Bowling Alone: The collapse and revival of American community. New York: Simon \& Schuster.

Putnam, R. D., Leonardi, R., Nanetti, R., \& Pavoncello, F. (1983). Explaining institutional secrets: the case of Italian regional government. The American Political Science Review, 77, 1, 55-74.

Putnam, R. D., Leonardi, R., \& Nanetti, R.Y. (1993). Making democracy work: Civic traditions in modern Italy. New Jersey: Princeton University press.

Reed, D., McGee, D., Yano, K., \& Feinleib, M. (1983). Social Networks and Coronary Heart Disease among Japanese Men in Hawaii. A J Epidemiol, 117, 384-396.

Rogers, E. (1983). Diffusion of Innovations. New York: Free Press.

Sampson, R. J., Raudenbush, S. W., \& Earls, F. (1997). Neighborhoods and Violent Crime: a Multilevel Study of Collective Efficacy. Science, 277, 918-924.

Seeman, T. E., Berkman, L. F., Kohout, F., LaCroix, A., Glynn, R., \& Blazer, D. (1993). Intercommunity Variations in the Association between Social Ties and Mortality in the Elderly. A Comparative Analysis of Three Communities. Ann Epidemiol, 3, 325-335.

Segerstrom, S., \& Miller, G. (2004). Psychological Stress and the Human Immune System: A Meta-Analytic Study of 30 Years of Inquiry. Psychol Bul, 130 (4), 601-630.

Siahpush, M., Borland, R., Taylor, J., Singh, G. K., Ansari, Z., \& Serraglio, A. (2006). The association of smoking with perception of income inequality, relative material well-being, and social capital. Soc Sci Med, 63, 2801-2812.

Tesh, S. N. (1988). Hidden Arguments: Political Ideology and Disease Prevention Policy. New Brunswick, NJ: Rutgers University Press.

Veenstra, G. (2000). Social capital, SES and health: an individual-level analysis. Soc Sci Med, 50, 619-629.

Veenstra, G. (2002). Social capital and health (plus wealth, income inequality and regional health governance). Soc Sci Med, 54, 849-868.

Wakefield, S. E. L., \& Poland, B. (2005). Family, friend or foe? Critical reflections on the relevance and role of social capital in health promotion and community development. Soc Sci Med, 60, 2819-2832.

Wilkinson, R. G. (1996). Unhealthy Societies: The Afflictions of Inequality. London: Routledge.

Wilkinson, R. G. (1999a). Income inequality, social cohesion, and health: clarifying the theory: a reply to Muntaner and Lynch. Int J Health Serv, 29 (3), 525-543.

Wilkinson, R. G. (1999b). The culture of inequality. In I. Kawachi, B. Kennedy, \& R. G. Wilkinson (Eds.), The Society and Population Health Reader: Income inequality and health. New York: New Press.

Wilkinson, R. G. (2002). L'inégalité nuit gravement à la santé. Paris : Éditions Casini. 